\title{
Effect of catalyst and reaction conditions on aromatic monomer yields, product distribution, and sugar yields during lignin hydrogenolysis of silver birch wood
}

\section{Authors: Thanaphong Phongpreecha, Kendall F. Christy, Sandip K. Singh, Pengchao Hao, David B. Hodge}

(C) This manuscript version is made available under the CC-BY-NC-ND 4.0 license https:// creativecommons.org/licenses/by-nc-nd/4.0/

Phongpreecha, Thanaphong, Kendall F. Christy, Sandip K. Singh, Pengchao Hao, and David B. Hodge. "Effect of Catalyst and Reaction Conditions on Aromatic Monomer Yields, Product Distribution, and Sugar Yields During Lignin Hydrogenolysis of Silver Birch Wood." Bioresource Technology 316 (November 2020): 123907. doi:10.1016/j.biortech.2020.123907. 


\title{
Effect of Catalyst and Reaction Conditions on Aromatic Monomer Yields, Product Distribution, and Sugar Yields During Lignin Hydrogenolysis of Silver Birch Wood
}

Thanaphong Phongpreecha, ${ }^{1}$ Kendall F. Christy, ${ }^{2}$ Sandip K. Singh, ${ }^{3}$ Pengchao Hao, ${ }^{4}$ David B. Hodge, $3,5^{*}$

${ }^{1}$ School of Medicine, Stanford University, Stanford, California 94305, United States

${ }^{2}$ Department of Chemical Engineering and Materials Science, Michigan State University

${ }^{3}$ Chemical \& Biological Engineering Department, Montana State University

${ }^{4}$ Department of Chemistry, Michigan State University

${ }^{5}$ Division of Sustainable Process Engineering, Luleå University of Technology, Luleå, Sweden

* corresponding author

Email: david.hodge3@montana.edu

\begin{abstract}
The impact of catalyst choice and reaction conditions during catalytic hydrogenolysis of silver birch biomass for their effect on aromatic monomer yields and selectivities, lignin removal, and sugar yields from enzymatic hydrolysis. At a reaction temperature of $220^{\circ} \mathrm{C}$ with no supplemental $\mathrm{H}_{2}$, it was demonstrated that both $\mathrm{Co} / \mathrm{C}$ and $\mathrm{Ni} / \mathrm{C}$ exhibited aromatic monomer yields of $>50 \%$, which were close to the theoretical maximum expected for the lignin based on total $\beta-\mathrm{O}-4$ content and exhibited high selectivities for 4-propylguaiacol and 4-propylsyringol at $220^{\circ} \mathrm{C} . \mathrm{Pd} / \mathrm{C}$ exhibited a significantly different set of products, and using a model lignin dimer, showed a product profile that shifted upon inclusion of supplemental $\mathrm{H}_{2}$, suggesting that the generation of surface hydrogen is critical for this catalyst system. Lignin removal during hydrogenolysis could be correlated to glucose yields and inclusion of lignin depolymerizing catalysts significantly improves lignin removal and subsequent enzymatic hydrolysis yields.
\end{abstract}

Keywords: lignin valorization, pretreatment, enzymatic hydrolysis, hydrogenolysis 


\section{Introduction}

The plant cell walls of lignocellulosic biomass are comprised primarily of the structural polymers cellulose, hemicellulose, and lignin and represent an enormous potential source of renewable carbon for the production of fuels, chemicals, and materials (Walton, 1994). While a number of processing approaches have been developed that optimally deconstruct the polysaccharide fraction to monomers for subsequent conversion to biofuels and biobased products, strategies for the fractionation and/or deconstruction and conversion of lignin, which can comprise more than 25\% mass of the biomass (Boerjan et al., 2003), may also be required to add value to the overall process. One of the methods is depolymerization of lignin to aromatic monomers through hydrogenolysis, in which the products are typically followed by hydrodeoxygenation in a one-pot reaction (Schutyser et al., 2018; Zakzeski et al., 2010). These approaches have seen significant attention in the past several years due to its ability to process whole biomass, i.e. the lignin valorization step has become pretreatment step in itself, showing limited condensation in certain conditions, and the compatibility with hydrogen transfer reactions, which allows it to leverage other hydrogen sources than pressurized gas (Deuss et al., 2015; Besse et al., 2017; Huang et al., 2015). A number of catalysts for the reaction have been proposed and shown to give high monomer yields at high product selectivities including $\mathrm{Ni}, \mathrm{Pd}$, and Ru-based catalysts (Schutyser et al., 2018). However, different studies using different lignin sources, conditions, and catalysts have resulted in not just monomer yields and, sometimes, product types that are not comparable, but also the impact on the pretreated biomass. This lack of benchmarking hinders the process of catalyst selection and design. Therefore, the present study aims to fill this gap by determining the efficacy of different supported metal catalysts on both monomer yields and quality of the pretreated hardwood biomass by a mean of enzymatic hydrolysis. The reaction is performed using hydrogen transfer from the selected solvent, which is ethanol or $i$-propanol in this work.

Early dedicated lignin hydrogenolysis studies were performed by Pepper et al., where it was shown that using whole softwood biomass as a substrate, monomer yields as high as $22 \%$ could be achieved using Raney $\mathrm{Ni}$ as the catalyst with water/dioxane (50:50 vol/vol) as the solvent (Pepper \& Lee, 1969b; Pepper \& Lee, 1970). Since then, there has been significant interest in hydrogenolysis including identifying new catalysts, solvents, and new hydrogen sources. 
Arguably, the reaction gains the most traction when it was demonstrated that using Ni/C with hardwood and alcohol solvents, lignin monomer as high as $50 \%$ were achieved with $>90 \%$ selectivity [9]. Many other studies using similar conditions with $\mathrm{Ni} / \mathrm{C}$ have shown similarly high yields ranging from $26 \%$ to as high as $90 \%$ depending on biomass type, lignin properties, and reaction conditions (Barta et al., 2010; Shuai et al., 2016). Other supported transition metal catalysts also have shown promising results, for example $\mathrm{Pd} / \mathrm{C}, \mathrm{Ru} / \mathrm{C}, \mathrm{Pt} / \mathrm{C}$, and many other transition metal alloys (Gao et al., 2016; Klein et al., 2015; Parsell et al., 2015; Ye et al., 2012; Zhang et al., 2014). These indicate that there are many possible transition metals, possibly more that have not been investigated, that could effectively perform lignin hydrogenolysis.

Many of the previously published experimental studies on hydrogenolysis reactions did not use $\mathrm{H}_{2}$ as a hydrogen source, but instead relied on the hydrogen transfer mechanism (catalytic transfer hydrogenolysis), such as from alcohols (Besse et al., 2017; Song et al., 2013), formic acid (Oregui-Bengoechea et al., 2017), and dioxane (Gao et al., 2016), each of which involves different hydrogen transfer mechanisms. One of the advantages of the process is that it does not require high pressure (e.g., $>1 \mathrm{MPa})$ as typically used when utilizing molecular hydrogen. However, this the efficacy of the reaction would also partly depend on the alcohol reforming activity of the catalyst. As alcohols are the most commonly used hydrogen donors and ethanol will be used in the present study during whole biomass hydrogenolysis studies, it is worth discussing about the capability of ethanol reforming of some of transition metal catalysts. Ethanol reforming converts ethanol to syngas and potentially other short alkanes and is optimally conducted at temperatures in the range of $600-800^{\circ} \mathrm{C}$ (Konsolakis et al., 2016; Zanchet et al., 2015). Hydrogen adsorbed on the surface could serve as the source for lignin hydrogenolysis. Mechanistically, ethanol reforming is a complex reaction process that involves several steps including molecular decomposition, water activation, and oxidation of the adsorbed carbon species (Zanchet et al., 2015). Metals that are typically used include, Ni, Co, Fe, Cu, Pt, Pd, and Rh (Hou et al., 2015; Konsolakis et al., 2016; Li et al., 2008; Zanchet et al., 2015). As such, these metals could have potential for lignin hydrogenolysis. Nevertheless, it should be noted that some of the metals have different decomposition mechanisms compared to others. For example, it has been demonstrated that on $\mathrm{Ni}$ and Co surfaces, ethanol first loses the hydroxyl hydrogen, 
resulting in $\mathrm{CH}_{3} \mathrm{CH}_{2} \mathrm{O} \cdot$ as the adsorbing species, whereas on $\mathrm{Pt}$ and $\mathrm{Pd}$ surfaces, hydrogen abstraction first occurs at the $\alpha$-carbon position, resulting in $\mathrm{CH}_{3} \dot{\mathrm{C}} \mathrm{HOH}$ as the adsorbing species (Zanchet et al., 2015). These adsorbing species are likely to have different affinities to the metal surface. Previous studies have proposed that adsorbing species, particularly ones with stronger interactions with the catalyst, could sterically block lignins from surface and be responsible for lower hydrogenolysis yields (Wang \& Rinaldi, 2012). Therefore, the low/high final monomer yields could be partly attributed to the reforming reaction pathways on the catalyst surface.

Regardless of catalyst and conditions, a common trait among all the examples that resulted in relatively high monomer yields is that a high-quality lignin, i.e. high $\beta-\mathrm{O}-4$ content, was used as a substrate. This is in agreement with studies indicating that $\mathrm{C}-\mathrm{O}$ ether bonds in lignin are significantly more susceptible to cleavage than C-C bonds (Kim et al., 2011); additionally, investigation of the reaction pathways from some of the catalysts (using the moderate temperatures of $\sim 200^{\circ} \mathrm{C}$ ) indicate that the products are primarily from cleavage of the $\beta-\mathrm{O}-4$ bond (Anderson et al., 2017). High-quality lignins are extracted in situ during the hydrogenolysis reaction of biomass, where lignin is solubilized by the organic solvent. This is because lignins subjected to prior chemical processing (e.g., dilute acid pretreatment, organosolv pretreatment, kraft pulping, etc.) are substantially modified with lower $\beta-\mathrm{O}-4$ contents, while $\mathrm{C}-\mathrm{C}$ bonds are formed (Gellerstedt et al., 2004; Samuel et al., 2010). In the present study, whole biomass was used as a reaction substrate to maximize monomer yields, while select conditions employed a model $\beta-\mathrm{O}-4$ dimer.

Using biomass as a substrate implies that the lignin valorization process acts as a delignification step, which may enable generation of high yields of monomeric sugars from the structural polysaccharides (Bosch et al., 2017; Huang et al., 2016; Rinaldi, 2017) to allow for integrated deconstruction of both lignin and polysaccharides. As such, apart from the aromatic monomer yields from the lignin, the process can also be evaluated for sugar release during enzymatic hydrolysis. Some of the factors that could impact enzymatic hydrolysis yields include lignin content, hemicellulose content, polysaccharide accessibility, and the cell wall's porosity (Williams et al., 2017). Lignin inhibits enzyme accessibility and its removal is well known to be vital for enzymatic hydrolysis. However, it should be noted that it is not in a linear relationship with sugar yields as certain biomass sources and pretreatment do not require high removals to 
obtain high sugars (Yang \& Wyman, 2004). Structural changes that occur during pretreatment such as lignin redeposition onto surfaces (Selig et al., 2007) and changes in cell wall porosity have been shown to affect sugar yields (Crowe et al., 2017; Williams et al., 2017). Without addition of catalysts, the lignin valorization process using biomass substrate is an organosolv pretreatment. Previous work with ethanol organosolv pretreatments typically employ ethanolwater mixtures and addition of a mineral or organic acid to catalyze hemicellulose depolymerization (Bär et al., 2018). The pretreatments have been demonstrated to reduce lignin to as low as 5\% depending on the severity. In the present work, no acid is added, and hence the effect from catalyst on this process will be assessed by lignin removal, xylan removal, and enzymatic hydrolysis of the pretreated biomass.

In summary, previous studies have suggested that several transition metal catalysts can be used to perform lignin hydrogenolysis using whole biomass as a feedstock, particularly through hydrogen transfer reactions. However, due to diversity of lignin sources, pretreatments, and reaction conditions, it has been difficult in determine the efficacy of different supported metals catalysts using the criteria of both aromatic monomer yields through catalytic hydrogenolysis and sugar monomer yield through the treatments impact as a delignifying pretreatment. Therefore, in the present study different metal/C catalysts, particularly those that have been shown to possess ethanol reforming capability, will be compared using the same source of lignin, from which monomer yields, characteristics of pretreated biomass, and enzymatic hydrolysis yields will be determined. The metals include $\mathrm{Fe}, \mathrm{Co}, \mathrm{Ni}, \mathrm{Cu}, \mathrm{Zn}, \mathrm{Ru}, \mathrm{Pd}$, and Ag. Additionally, the same treatment will be performed on lignins obtained after alkali pretreatment to demonstrate the importance of the quality of the substrate. Finally, the impact of hydrogen addition on selectivity and yields is assessed for a model lignin dimer for Pd. Specifically, novel components of this work are: (1) providing a side-by-side comparison of these catalysts and (2) linking reaction conditions and catalysts to compositional changes and further to the deconstruction to aromatic monomers and subsequent enzymatic hydrolysis yields of sugars. 


\section{Materials and Methods}

\subsection{Biomass and Lignins}

\subsubsection{Biomass Feedstock and Composition Analysis}

The biomass used for the present work is silver birch (Betula pendula Roth.) grown in northern Sweden and supplied by Curt Lindström (Smurfit-Kappa Kraftliner AB, Piteå, Sweden) and has been subjected to detailed characterization in our prior work (Bansal et al., 2016; Stoklosa \& Hodge, 2015). The biomass was milled to $\leq 5 \mathrm{~mm}$ size (Wiley mini-mill, Thomas Scientific) and air-dried to $\leq 5 \%$ moisture. The composition of untreated biomass, delignified biomass, and recovered lignins was determined using the NREL Laboratory Analytical Protocol (LAP) NREL/TP-510-42618 (Sluiter et al., 2004).

\subsubsection{Lignin Dimer Synthesis}

A characteristic lignin dimer comprising a guaiacol linked to guaiacylglycerol with a $\beta-\mathrm{O}-4$ bond (guaiacylglycerol- $\beta$-guaiacyl ether) was synthesized as reported in the literature (Hao, 2018) and verified by NMR.

\subsection{Catalytic Hydrogenolysis of Whole Biomass, Lignin, and Lignin Dimer}

Catalysts with a $10 \%$ metal loading metals/C was synthesized by incipient wetness where the metals were sourced from $\mathrm{Fe}\left(\mathrm{NO}_{3}\right)_{3} \cdot 9 \mathrm{H}_{2} \mathrm{O}, \mathrm{Co}\left(\mathrm{NO}_{3}\right)_{2} \cdot 6 \mathrm{H}_{2} \mathrm{O}, \mathrm{Ni}\left(\mathrm{NO}_{3}\right)_{2} \cdot 6 \mathrm{H}_{2} \mathrm{O}$, $\mathrm{Cu}\left(\mathrm{NO}_{3}\right)_{2} \cdot 3 \mathrm{H}_{2} \mathrm{O}, \mathrm{Zn}\left(\mathrm{NO}_{3}\right)_{2} \cdot 6 \mathrm{H}_{2} \mathrm{O}, \mathrm{AgNO}_{3}$, and $\mathrm{RuCl}_{3} \cdot \mathrm{xH}_{2} \mathrm{O}$, where $\mathrm{x}$ is estimated as 0.5 , which is an average degree of hydration reported for the product (Sigma-Aldrich). For example, $2.76 \mathrm{~g}$ of $\mathrm{Ni}\left(\mathrm{NO}_{3}\right)_{2} \cdot 6 \mathrm{H}_{2} \mathrm{O}$ was added to $8 \mathrm{~g}$ deionized water and stirred until well mixed. The solution was then added dropwise to $5 \mathrm{~g}$ of activated carbon (Darco ${ }^{\circledR} \mathrm{G}-60$, Aldrich, water absorption capacity of $2.1 \mathrm{~mL} / \mathrm{g}$ ). The mixture was kept wet at room temperature for $24 \mathrm{~h}$ before drying overnight at $100^{\circ} \mathrm{C}$. Then it was calcined at $400^{\circ} \mathrm{C}$ under nitrogen atmosphere for 4 hours and reduced at $400^{\circ} \mathrm{C}$ under $10 \% \mathrm{H}_{2}$ in an $\mathrm{Ar}$ atmosphere, both of which used at a temperature ramp of $6.25^{\circ} \mathrm{C} / \mathrm{min} . \mathrm{Pd} / \mathrm{C}$ was purchased from Sigma-Aldrich $(10 \% \mathrm{Pd}$ on carbon by weight, product number 205699). The reduced catalysts were stored and weighed in an anaerobic glove box.

For the hydrogenolysis reaction, $200 \mathrm{mg}$ of biomass, $30 \mathrm{mg}$ of catalyst, and $4 \mathrm{~mL}$ of ethanol were charged to a $10-\mathrm{mL}$ passivated stainless steel reactor while in an anaerobic glove box to 
prevent oxygen introduction to the reactor. Reactors were sealed and submerged in a fluidized sand bath (Techne SBS-4, Techne Equipment, Saffordshire, UK) set at 200 or $220^{\circ} \mathrm{C}$ for $6 \mathrm{hr}$. The resulting liquid was collected, filtered, and analyzed by GC/MS (Agilent 7890A / 5975C) equipped with an Agilent DB-WAXETR column (30 $\mathrm{m} \times 0.250 \mathrm{~mm} \times 0.25 \mu \mathrm{m})$ with a 1:1000 split. The temperature program consists of first holding at $60^{\circ} \mathrm{C}$ for $3 \mathrm{~min}$, ramping up at $40^{\circ} \mathrm{C} / \mathrm{min}$ to $260^{\circ} \mathrm{C}$ where it is held for $2.5 \mathrm{~min}$. Product yields were determined as mass products per mass original Klason lignin using standard curves constructed from pure monomers.

Specifically, 4-propylguaiacol, isoeugenol, 4-ethylguaiacol, and syringol were purchased from Sigma-Aldrich. The 4-propylsyringol and 4-propenylsyringol were synthesized according to Parsell et al. (2015) using the hydrogenation approach of Curti et al. (2006). Dihydroconiferyl alcohol, dihydrosinapyl alcohol, and 4-ethyl syringol, were estimated using the same response factor as 4-propylsyringol. After collecting the liquid, the residual biomass was washed with excess water and air-dried at room temperature. For hydrogenolysis of the lignin dimer, the mass of the catalyst was $10 \% \mathrm{wt}$. of the dimer $(20 \mathrm{mg})$. The selectivity of the products was estimated as the ratios of the monomer peaks. The dimer purity was $89 \%$ with the rest primarily guaiacol, and the selectivity is corrected using the known guaiacol peak area of the dimer.

\subsection{Enzymatic Hydrolysis}

Approximately $10 \pm 0.3 \mathrm{mg}$ of the pretreated biomass was added to $1.5-\mathrm{mL}$ Eppendorf ${ }^{\circledR}$ SafeLock microcentrifuge tubes. The hydrolysis was performed at a $5 \%(\mathrm{w} / \mathrm{v})$ solid loading with the Na-citrate buffer at a concentration of $50 \mathrm{mM}$ and $\mathrm{pH}$ of 5.5 was added based on the findings of Lan et al. (Lan et al., 2013). To prevent bacterial contamination during hydrolysis, tetracycline and cycloheximide was added at a concentration of $40 \mu \mathrm{g} / \mathrm{mL}$ and $60 \mu \mathrm{g} / \mathrm{mL}$, respectively. Enzyme cocktails consisted of Cellic CTec2 and HTec2 (Novozymes A/S, Bagsævard, Denmark) and were added at a ratio of 2:1, respectively. For all experiments, the total enzyme loading was $20 \mathrm{mg}$ total proteins per gram of glucan in the biomass sample. The reaction was performed in a shaking incubator at $50^{\circ} \mathrm{C}$ at $160 \mathrm{rpm}$. After 72 hours, samples were collected and analyzed for glucose and xylose using HPLC as reported in our prior work (Williams \& Hodge, 2014). Hydrolysis experiments were performed in duplicate. The sugar yields were determined based on 
the glucan and xylan available in the residual biomass as determined using composition analysis according to NREL/TP-510-42618.

\subsection{X-Ray Photoelectron Spectroscopy (XPS)}

The XPS surface elemental identification and quantification of sample untreated and pretreated biomass samples was performed using a Physical Electronics 5600 electron spectrometer equipped with a monochromatic Al Ka $(\sim 1400 \mathrm{eV}) \mathrm{X}$-Ray source and operated under ultra-high vacuum ( $\sim 10^{-10}$ torr). Spectra were recorded using a hemispherical analyzer and the atomic concentration of carbon and oxygen atoms were characterized by the integration of peak area and the relative ratio of $\mathrm{C} / \mathrm{O}$ on the surface were determined.

\section{Results \& Discussion}

\subsection{Monomer Yields from Native Lignin in Biomass by Hydrogenolysis using Diverse Metal Catalysts}

In the first part of this work, deconstruction of silver birch was performed using a range of transition metal catalysts in ethanol as the solvent and no supplemental $\mathrm{H}_{2}$ addition and the impact on product yields and selectivities were assessed. Maximum theoretical monomer yields by cleavage of $\beta-\mathrm{O}-4$ were estimated previously for this lignin as $\sim 50 \%$ from quantified $\beta-\mathrm{O}-4$ content and demonstrated as achievable using depolymerization by thioacidolysis (Phongpreecha et al., 2017). It can be observed from Fig. 1 that the highest monomer yields achieved by using whole biomass as a substrate were obtained from $\mathrm{Co}$ and $\mathrm{Ni}$ catalysts at $\sim 50 \%$ with $\mathrm{Ru}$ and $\mathrm{Pd}$ also resulting in relatively high yields. Not using catalyst resulted in negligible generation of monomers. Notably, there is a large difference between the temperature of $200^{\circ} \mathrm{C}$ and $220^{\circ} \mathrm{C}$. This is likely due to that the reaction at $220^{\circ} \mathrm{C}$ resulted in significantly higher ethanol reforming activity as there was noticeably more pressure upon completion of the reaction. By arranging the results according to groups in periodic table (Fig. 1), a volcano-plot like shape can be observed, particularly for period 1 where a sufficient number of metals were investigated. This suggests that the energetics related to adsorption and desorption of species on Co and $\mathrm{Ni}$ resulted in optimal reactivity. Interestingly, $\mathrm{Co} / \mathrm{C}$ catalyst was also shown to yield the most $\mathrm{H}_{2}$ during low temperature ethanol reforming $\left(400^{\circ} \mathrm{C}\right)$ (Konsolakis et al., 2016). 
For each of the catalysts in Fig. 1, we can observe that not all the catalysts that were previously reported for ethanol reforming (all except $\mathrm{Zn}$ and $\mathrm{Ag}$ ) perform well, including Fe and $\mathrm{Cu}$. For $\mathrm{Fe}$, the low yields were likely due to the high affinity of Fe for oxygen. Based on a previous computation study on the ethanol reforming mechanism, it is likely that ethoxy adsorbing species are formed at the interface (Konsolakis et al., 2016). At the temperatures in the present study (compared to $800^{\circ} \mathrm{C}$, where $\mathrm{H}_{2}$ formation from $\mathrm{Fe}$ was comparable to $\mathrm{Co}$ and $\mathrm{Ni}$ ), the adsorbing species are likely to adhere to the Fe surface. On the other side of the volcano, the reason for the poor performance of $\mathrm{Cu}$ is likely to be the opposite of the Fe. Studies have suggested low adsorption energies for ethanol on $\mathrm{Cu}$ surfaces. Therefore, higher temperatures than the current study $\left(800^{\circ} \mathrm{C}\right)$ were typically used for ethanol reforming with $\mathrm{Cu}$ to produce high amounts of $\mathrm{H}_{2}$ likely by improving kinetics and lowering the solvent-solvent interactions (Konsolakis et al., 2016). Apart from this, the interaction between lignin and the $\mathrm{Cu}$ itself was also low. Our prior work using density functional theory (DFT) calculations has demonstrated that a lignin dimer solvated in ethanol at $50^{\circ} \mathrm{C}$ does not adsorb on $\mathrm{Cu}(111)$ (Phongpreecha et al., 2019). Therefore, higher temperature should be used for $\mathrm{Cu}$ to reduce the solvent-solute interactions. In agreement with this analysis, previous studies with lignin using $\mathrm{Cu}$-based catalysts have shown that a temperature of $300^{\circ} \mathrm{C}$ was sufficient for $\mathrm{Cu}$ to generate significant $\mathrm{H}$ from methanol, resulting in almost complete lignin conversion (Barta \& Ford, 2014; Macala et al., 2009). However, due to the high temperatures, the products were also completely hydrogenated.

Apart from metals that were typically used for ethanol reforming, $\mathrm{Zn}$ and Ag were also investigated. It can be observed that both were capable of generating yields of $\sim 7 \%$ monomer yields at $220^{\circ} \mathrm{C}$, similar to $\mathrm{Cu}$ (Fig. 1), and higher than those obtained with the control with no catalyst. For $\mathrm{Zn}$, it has been previously used as a co-catalyst with $\mathrm{Pd}$, where using multiple characterization techniques it was found that $\mathrm{Zn}$ deposited and formed a complex at $-\mathrm{OH}$ sites on activated carbon, where it was proposed to facilitate reaction either by facilitating binding with hydroxyl groups of lignin or it could desorb from the surface as $\mathrm{Zn}^{2+}$ ions and be deposited back upon cooling down. Nevertheless, in the present study, it is clear that insufficient hydrogen was generated for both of these catalysts as evidenced by the low yields while the products were virtually all composed of unsaturated propenyl side chains. 
In the context of product types and distribution, it can be seen from Fig. 1 that at $220^{\circ} \mathrm{C}$, the metals $\mathrm{Co}, \mathrm{Ni}, \mathrm{Ru}$, and Pd resulted in mostly 4-propylguaiacol (4-PG) and 4-propylsyringol (4PS). The $\mathrm{Cu}$ and $\mathrm{Ni}$ gave the highest yields of saturated products and also the highest selectivity based on the native lignin's units ( $>96 \%$ for both catalysts). In the native lignin, there are primarily two units, i.e. syringyl and guaiacyl, where the former has two methoxyl groups on its aromatic ring and the latter has one. The monomer products from each of these groups are expected to retain its original methoxyl group(s). Given that the $\mathrm{S} / \mathrm{G}$ ratio of the birch used in this study is 2.4 (mol/mol) from thioacidolysis (Bansal et al., 2016) but the $\mathrm{S} / \mathrm{G}$ ratio of the products from the Co and Ni catalysts is $4.1(\mathrm{~mol} / \mathrm{mol})$ on average, this implies that more of the lignin's syringyl units underwent hydrogenolysis or, alternatively, that under these conditions more of the guaiacyl units undergo repolymerization. This could be due to several reasons. For example, the $\beta-O-4$ linked guaiacyl units in lignin could be less susceptible to hydrogenolysis or guaiacyl units liberated from the polymer by hydrogenolysis are susceptible to repolymerization (e.g., at the unsubstituted methoxyl position in the aromatic ring). As the reaction primarily aims at cleaving $\beta-\mathrm{O}-4$, to generate monomer it is required that both ends of the unit are $\beta-\mathrm{O}-4$ linkage. This could be supported by the understanding that during lignin biosynthesis, higher syringyl content results in higher $\beta-\mathrm{O}-4$ bond abundance (Robinson \& Mansfield, 2009). Apart from these, a major fraction of the monomers from catalysts that resulted in low yield are unsaturated products, including 4-propenylguaiacol (4-PnylS) and 4-propenylsyringol (4-PnylG). The same is true for the reaction at $200^{\circ} \mathrm{C}$ (Fig. 1). Both findings suggest insufficient generation of hydrogen adatoms in those conditions.

Among all the catalysts, $\mathrm{Pd}$ is the only catalyst that gave unique products including 4ethylguaiacol (4-EG), 4-ethylsyringol (4-ES), and a small amount of syringol (0.4\% yield) under the conditions tested. Additionally, unlike other catalysts that were reported to yield similar products both with and without added $\mathrm{H}_{2}$ added such as Ni/C. The products 4-EG and 4ES were not reported in previous studies using that use $\mathrm{Pd} / \mathrm{C}$ with $\mathrm{H}_{2}$ gas. To ensure that our reactions and product identification is accurate, a lignin dimer (guaiacylglycerol- $\beta$-guaiacyl ether) was employed for further investigation. The lignin dimer was used to eliminate any other possible side reactions or contributions from other linkages in real lignin. Figure 2 shows the different products obtained from lignin dimer hydrogenolysis on $\mathrm{Pd} / \mathrm{C}$ with and without added $\mathrm{H}_{2}$ 
gas. Without supplemental $\mathrm{H}_{2}$ addition, product profile similar to that obtained from lignin (Fig. 1) was generated. However, addition of $\mathrm{H}_{2}$ resulted in products (dihydroconiferyl alcohol) that are similar to previous studies (Bosch et al., 2015; Pepper et al., 1966). Specifically, using different initial $\mathrm{H}_{2}$ pressures, it can be observed that at lower pressure, 4-PG was produced (possibly more if the pressure was ever lower). However, it totally disappears at high pressure. These suggest that lignin on $\mathrm{Pd} / \mathrm{C}$ undergoes a different reaction pathway in the presence of $\mathrm{H}_{2}$ and was likely dependent of the hydrogen coverage at the metal-liquid interface. Further probing the effects of hydrogen coverage on different catalysts would make for an interesting future study. It should be noted that the temperature of the reactions employing $\mathrm{H}_{2}$ gas were slightly lower $\left(150^{\circ} \mathrm{C}\right)$ due to reactor limitations, while the reaction using no supplemental $\mathrm{H}_{2}$ was performed at higher temperature $\left(190^{\circ} \mathrm{C}\right)$ to ensure sufficient hydrogen reforming activity. The longer reaction time was used for the reactions employing supplemental $\mathrm{H}_{2}$ to determine if the reaction products would change. It should be noted that prior work found that prior work found that increasing temperature improved the selectivity for 4-propylguaiacol and 4-propylsyringol over the dialcohols using Raney Ni in 50\% dioxane/water (Pepper \& Steck, 1963).

\subsection{Enzymatic Hydrolysis and Characterization of the Pretreated Biomass}

Biomass pretreated by hydrogenolysis was next subjected to enzymatic hydrolysis to assess the impact of reaction conditions on bulk changes in the composition of the biomass, the potential for conversion of the remaining polysaccharides, and correlations between properties and product yields.

A summary of percent removal (i.e., percentage solubilized following hydrogenolysis) of the main cell wall biopolymer components after pretreatment is shown in Fig. 3A for lignin and 3B for xylan. Overall, the cellulose was nearly completely preserved even after the reaction at $220^{\circ} \mathrm{C}$ (data not shown). However, hemicellulose was partially solubilized, particularly at the higher temperature. It can be observed that the inclusion of catalysts further increases the loss of xylan, presumably through its hydrogenolysis (Fig. 3B). Hydrogenolysis of xylan under similar conditions was previously reported to result in soluble sugars without further hydrogenation $[9,17]$, which should theoretically be recoverable from the liquid fraction. Significant differences can be observed for lignin removal between the different catalysts with all catalysts exhibiting 
more lignin removal than the control (i.e., no catalyst) case (Fig. 3A). Interestingly, the lignin removal shows identical trends for both temperatures tested and the lignin removal shows a similar, volcano-like plot comparable to what is observed for the aromatic monomer yields (Fig. 1), indicating that the phenomena of lignin solubilization/removal and depolymerization and linked. Following hydrogenolysis, significant macroscopic differences in the biomass were observed, with the biomass becoming significantly darker after pretreatment, despite compositional analysis indicating that pretreatment without catalyst at $220^{\circ} \mathrm{C}$ removes $42 \%$ of the lignin (Fig. 3A). As reactions were performed in batch reactors, one interpretation of this result is that a fraction of the that was not ethanol-soluble after the reactor was cooled was redeposited on biomass surface, which has been observed previously in dilute acid pretreatment and is expected to decrease cellulose accessibility (Selig et al., 2007).

Next, XPS was applied to assess the relative ratio of carbon to oxygen on the surface of the biomass and these were related the bulk compositional changes (Table 1). It was hypothesized that in treatments with low lignin depolymerization yields (e.g., no catalyst, $\mathrm{Cu}, \mathrm{Zn}, \mathrm{Ag})$ that a significant fraction of the lignin may be solubilized or melted during the pretreatment, but could redeposit on biomass surfaces as the liquor cools since the reaction is performed in a batch system. If this were the case, then the surface $\mathrm{C} / \mathrm{O}$, which serves as a proxy for lignintocarbohydrate ratio, would be higher than would be expected based on the bulk composition. The results show that the $\mathrm{C} / \mathrm{O}$ decreases concurrently with increasing lignin removal (Table 1). These results are expected as lignins have may have $\mathrm{C} / \mathrm{O}$ ranging from $\sim 2.7-3.5$ depending on properties such as $\mathrm{S} / \mathrm{G}$ ratio and relative abundance of linkages. This is significantly higher than the predicted $\mathrm{C} / \mathrm{O}$ ratio for polysaccharides such as cellulose $(\mathrm{C} / \mathrm{O}=1.2)$ and xylan $(\mathrm{C} / \mathrm{O}=1.25)$. However, from these results it cannot be concluded that the surface lignin is more abundant that the bulk lignin content.

The impact of the pretreatment conditions and choice of catalyst on enzymatic hydrolysis yields is next evaluated with results presented in Fig. 4. Noticeably, with the exception of $\mathrm{Cu}$ and $\mathrm{Zn}$, a volcano-plot like behavior is apparent for the glucose yields (Fig. 4A). As the trends are comparable to the lignin removal, it is expected that the differences in the glucose hydrolysis yields are due to differences in lignin removal during the hydrogenolysis. A notable result is that without any catalyst, the glucose yields were only $31 \%$, whereas the glucose yields greater than 
$75 \%$ could be obtained from reactions that included $\mathrm{Co} / \mathrm{C}, \mathrm{Ni} / \mathrm{C}, \mathrm{Ru} / \mathrm{C}$, and $\mathrm{Pd} / \mathrm{C}$ using a temperature of $220^{\circ} \mathrm{C}$. It can be noted that the slightly higher glucose yields from the $\mathrm{Pd}$ and $\mathrm{Ru}$ catalysts were because they removed slightly more lignin (Fig. 4A). Xylose yields do not exhibit the same strong trends potentially because of the higher loss of xylan after pretreatment (Fig. 4B). Overall, this indicates that adding catalysts, such as $\mathrm{Co}, \mathrm{Ni}, \mathrm{Ru}$, and $\mathrm{Pd}$ catalysts did not only result in high monomers from lignin hydrogenolysis and side chain hydrodeoxygenation, but also significantly promote accessibility of enzymes to cellulose and hemicellulose.

\subsection{Correlations Between Properties and Product Yields}

Correlations between the data are next plotted to demonstrate how composition, aromatic monomer yields from hydrogenolysis, and glucose yields from enzymatic hydrogenolysis are related (Fig. 5). The first correlation between lignin removal and aromatic monomer yield (Fig. 5A) shows that at low monomer yields the monomer yield increases proportionally to the lignin removal. However, the monomer yield continues to increase while the lignin removal approaches an asymptotic maximum at approximately $75 \%$ lignin removal. This result from the linear region can be interpreted as first simultaneously solubilizing lignin and partially depolymerizing it to monomers as well as (unquantified) oligomers and dimers that are not likely to redeposit on the biomass. The second region whereby the monomer yield increases from $20 \%$ to $50 \%$ represents further depolymerization of ethanol-soluble oligomers to monomers and (unquantified) smaller oligomers and dimers. The next correlation is between lignin removal and glucose yields by enzymatic hydrolysis (Fig. 5B), which is both strong $\left(\mathrm{R}^{2}=0.824\right)$ and significant $\left(p<10^{-6}\right)$. The final correlation between lignin and xylan removal (Fig. 5C) shows that these pretreatment outcomes are also strongly correlated $\left(p<10^{-5}\right)$ and that the pretreatment conditions and catalysts that are effective at lignin removal are also effective at xylan removal to

yield a cellulose-rich pulp. It is well-established that lignin, as well as hemicellulose removal can be strong predictors of enzymatic hydrolysis yields (Yang and Wyman, 2004) as the removal of these cell wall biopolymers increases the accessibility of cellulose to hydrolytic enzymes.

\section{Conclusions}

Catalytic hydrogenolysis of biomass was performed using different supported metal catalysts and it was found that catalysts that resulted in high aromatic monomer yields and/or 
lignin solubilization tended to result in higher glucose yields and demonstrated that addition of catalysts have a large impact not on just monomer yields, but also on the efficacy of the pretreatment of the biomass. The use of a model lignin dimer using $\mathrm{Pd} / \mathrm{C}$ with or without supplemental $\mathrm{H}_{2}$ demonstrated the important role that the ethanol reforming reaction, and presumably surface hydrogen, plays in determining products yields and selectivities.

E-supplementary data of this work can be found in the online version of the paper.

\section{Declarations Author Contributions}

$\mathrm{TP}$ and DBH conceived the work and wrote the manuscript, TP and KFC performed the experimental work associated with the biomass hydrogenolysis and SKS prepared samples and analyzed results for XPS.

\section{Acknowledgements}

The authors would like to thank Dr. Recep Avci (Image and Chemical Analysis Laboratory, Montana State University) for performing XPS.

\section{Competing Interests}

The authors declare that we have no competing interests.

\section{Funding}

This work was supported through funding by the Northeast Sun Grant Institute of Excellence 2014 Competitive Grants Program. KFC was funded by the Michigan State University Honor's College.

\section{References}

1. Anderson, E.M., Stone, M.L., Katahira, R., Reed, M., Beckham, G.T., Román-Leshkov, Y. 2017. Flowthrough Reductive Catalytic Fractionation of Biomass. Joule, 1(3), 613-622. 
2. Bansal, N., Bhalla, A., Pattathil, S., Adelman, S.L., Hahn, M.G., Hodge, D.B., Hegg, E.L. 2016. Cell wall-associated transition metals improve alkaline-oxidative pretreatment in diverse hardwoods. Green Chem, 18(5), 1405-1415.

3. Bär, J., Phongpreecha, T., Singh, S.K., Yilmaz, M.K., Foster, C.E., Crowe, J.D., Hodge, D.B. 2018. Deconstruction of hybrid poplar to monomeric sugars and aromatics using ethanol organosolv fractionation. Biom Conv Bioref, 1-12.

4. Barta, K., Ford, P.C. 2014. Catalytic Conversion of Nonfood Woody Biomass Solids to Organic Liquids. Acc Chem Res, 47(5), 1503-1512.

5. Barta, K., Matson, T.D., Fettig, M.L., Scott, S.L., Iretskii, A.V., Ford, P.C. 2010. Catalytic disassembly of an organosolv lignin via hydrogen transfer from supercritical methanol. Green Chem, 12(9), 1640-1647.

6. Besse, X., Schuurman, Y., Guilhaume, N. 2017. Reactivity of lignin model compounds through hydrogen transfer catalysis in ethanol/water mixtures. Appl Catal B, 209, 265-272.

7. Boerjan, W., Ralph, J., Baucher, M. 2003. Lignin Biosynthesis. Ann Rev Plant Biol, 54(1), 519-546.

8. Bosch, S.V.d., Renders, T., Kennis, S., Koelewijn, S.F., Bossche, G.V.d., Vangeel, T., Deneyer, A., Depuydt, D., Courtin, C.M., Thevelein, J.M., Schutyser, W., Sels, B.F. 2017. Integrating lignin valorization and bio-ethanol production: on the role of $\mathrm{Ni}-\mathrm{Al} 2 \mathrm{O} 3$ catalyst pellets during lignin-first fractionation. Green Chem, 19(14), 3313-3326.

9. Bosch, S.V.d., Schutyser, W., Koelewijn, S.F., Renders, T., Courtin, C.M., Sels, B.F. 2015. Tuning the lignin oil $\mathrm{OH}$-content with $\mathrm{Ru}$ and $\mathrm{Pd}$ catalysts during lignin hydrogenolysis on birch wood. Chem Comm, 51(67), 13158-13161.

10. Crowe, J.D., Zarger, R.A., Hodge, D.B. 2017. Relating Nanoscale Accessibility within Plant Cell Walls to Improved Enzyme Hydrolysis Yields in Corn Stover Subjected to Diverse Pretreatments. J Agric Food Chem, 65(39), 8652-8662.

11. Curti, C., Zanardi, F., Battistini, L., Sartori, A., Rassu, G., Pinna, L., Casiraghi, G. 2006. Streamlined, Asymmetric Synthesis of 8,4'-Oxyneolignans. J Org Chem, 71(22), 8552-8558.

12. Deuss, P.J., Scott, M., Tran, F., Westwood, N.J., de Vries, J.G., Barta, K. 2015. Aromatic monomers by in situ conversion of reactive intermediates in the acid-catalyzed depolymerization of lignin. J Am Chem Soc, 137(23), 7456-7467. 
13. Gao, F., Webb, J.D., Sorek, H., Wemmer, D.E., Hartwig, J.F. 2016. Fragmentation of Lignin

Samples with Commercial Pd/C under Ambient Pressure of Hydrogen. ACS Catalysis. 6(11), 7385-7392.

14. Gellerstedt, G., Majtnerova, A., Zhang, L. 2004. Towards a new concept of lignin condensation in kraft pulping. Initial results. Compt Rend Biol, 327(9), 817-826.

15. Hao, P. 2018. Electrocatalytic Hydrogenation of Monomeric, Dimeric, and Polymeric Lignin

Model Compounds With Raney Nickel: Chemistry, Mechanistic, and Product Toxicity Studies. Ph.D. Thesis.

16. Hou, T., Zhang, S., Chen, Y., Wang, D., Cai, W. 2015. Hydrogen production from ethanol reforming: Catalysts and reaction mechanism. Ren Sus Energ Rev, 44, 132-148.

17. Huang, X., Korányi, T.I., Boot, M.D., Hensen, E.J.M. 2015. Ethanol as capping agent and formaldehyde scavenger for efficient depolymerization of lignin to aromatics. Green Chem, 17(11), 4941-4950.

18. Huang, X., Zhu, J., Korányi, T.I., Boot, M.D., Hensen, E.J.M. 2016. Effective Release of Lignin Fragments from Lignocellulose by Lewis Acid Metal Triflates in the Lignin-First Approach. ChemSusChem, 9(23), 3262-3267.

19. Kim, S., Chmely, S.C., Nimlos, M.R., Bomble, Y.J., Foust, T.D., Paton, R.S., Beckham, G.T.

2011. Computational Study of Bond Dissociation Enthalpies for a Large Range of Native and Modified Lignins. J Phys Chem Lett, 2(22), 2846-2852.

20. Klein, I., Saha, B., Abu-Omar, M.M. 2015. Lignin depolymerization over Ni/C catalyst in methanol, a continuation: effect of substrate and catalyst loading. Catal Sci Technol, 5(6), 3242-3245.

21. Konsolakis, M., Ioakimidis, Z., Kraia, T., Marnellos, G., Konsolakis, M., Ioakimidis, Z., Kraia, T., Marnellos, G.E. 2016. Hydrogen Production by Ethanol Steam Reforming (ESR) over $\mathrm{CeO}_{2}$ Supported Transition Metal (Fe, $\mathrm{Co}, \mathrm{Ni}, \mathrm{Cu}$ ) Catalysts: Insight into the StructureActivity Relationship. Catalysts, 6(3), 39.

22. Lan, T.Q., Lou, H., Zhu, J.Y. 2013. Enzymatic Saccharification of Lignocelluloses Should be Conducted at Elevated pH 5.2-6.2. Bioenerg Res, 6(2), 476-485. 
23. Li, W., Wang, H., Ren, Z., Wang, G., Bai, J. 2008. Co-production of hydrogen and multiwall carbon nanotubes from ethanol decomposition over Fe $/ \mathrm{Al}_{2} \mathrm{O}_{3}$ catalysts. Appl Catal B, 84(3), 433-439.

24. Macala, G.S., Matson, T.D., Johnson, C.L., Lewis, R.S., Iretskii, A.V., Ford, P.C. 2009. Hydrogen Transfer from Supercritical Methanol over a Solid Base Catalyst: A Model for Lignin Depolymerization. ChemSusChem, 2(3), 215-217.

25. Oregui-Bengoechea, M., Gandarias, I., Arias, P.L., Barth, T. 2017. Unraveling the Role of Formic Acid and the Type of Solvent in the Catalytic Conversion of Lignin: A Holistic Approach. ChemSusChem, 10(4), 754-766.

26. Parsell, T., Yohe, S., Degenstein, J., Jarrell, T., Klein, I., Gencer, E., Hewetson, B., Hurt, M., Kim, J.I., Choudhari, H., Saha, B., Meilan, R., Mosier, N., Ribeiro, F., Delgass, W.N., Chapple, C., Kenttämaa, H.I., Agrawal, R., Abu-Omar, M.M. 2015. A synergistic biorefinery based on catalytic conversion of lignin prior to cellulose starting from lignocellulosic biomass. Green Chem, 17(3), 1492-1499.

27. Pepper, J., Lee, Y. 1969. Lignin and related compounds. I. A comparative study of catalysts for lignin hydrogenolysis. Can J Chem, 47(5), 723-727.

28. Pepper, J., Steck, W. 1963. The effect of time and temperature on the hydrogenation of aspen lignin. Can J Chem, 41(11), 2867-2875.

29. Pepper, J.M., Lee, Y.W. 1969. Lignin and related compounds. I. A comparative study of catalysts for lignin hydrogenolysis. Can J Chem, 47(5), 723-727.

30. Pepper, J.M., Lee, Y.W. 1970. Lignin and related compounds. II. Studies using ruthenium and Raney nickel as catalysts for lignin hydrogenolysis. Can J Chem, 48(3), 477-479.

31. Phongpreecha, T., Liu, J., Hodge, D.B., Qi, Y. 2019. Adsorption of Lignin $\beta-O-4$ Dimers on Metal Surfaces in Vacuum and Solvated Environments. ACS Sus Chem Eng, 7(2), 26672678. 32. Rinaldi, R. 2017. A Tandem for Lignin-First Biorefinery. Joule, 1(3), 427-428.

33. Robinson, A.R., Mansfield, S.D. 2009. Rapid analysis of poplar lignin monomer composition by a streamlined thioacidolysis procedure and near-infrared reflectance-based prediction modeling. Plant J, 58(4), 706-714.

34. Samuel, R., Pu, Y., Raman, B., Ragauskas, A.J. 2010. Structural Characterization and Comparison of Switchgrass Ball-milled Lignin Before and After Dilute Acid Pretreatment. 
Appl Biochem Biotechnol, 162(1), 62-74.

35. Schutyser, W., Renders, T., Bosch, S.V.d., Koelewijn, S.F., T. Beckham, G., F. Sels, B. 2018. Chemicals from lignin: an interplay of lignocellulose fractionation, depolymerisation, and upgrading. Chem Soc Rev, 47(3), 852-908.

36. Selig, M.J., Viamajala, S., Decker, S.R., Tucker, M.P., Himmel, M.E., Vinzant, T.B. 2007. Deposition of lignin droplets produced during dilute acid pretreatment of maize stems retards enzymatic hydrolysis of cellulose. Biotechnol Prog, 23(6), 1333-9.

37. Shuai, L., Talebi Amiri, M., Questell-Santiago, Y.M., Héroguel, F., Li, Y., Kim, H., Heilan, R., Chapple, C., Ralph, J., Luterbacher, J.S. 2016. Formaldehyde stabilization facilitates lignin monomer production during biomass depolymerization. Science, 354(6310), 329-333.

38. Sluiter, A., Hames, B., Ruiz, R.O., Sluiter, J., Templeton, D. 2004. Determination of Structural Carbohydrates and Lignin in Biomass. NREL/TP-510-42618.

39. Song, Q., Wang, F., Cai, J., Wang, Y., Zhang, J., Yu, W., Xu, J. 2013. Lignin depolymerization (LDP) in alcohol over nickel-based catalysts via a fragmentationhydrogenolysis process. Energ Environ Sci, 6(3), 994-1007.

40. Stoklosa, R.J., Hodge, D.B. 2015. Fractionation and Improved Enzymatic Deconstruction of Hardwoods with Alkaline Delignification. Bioenerg Res, 8(3), 1224-1234.

41. Walton, J.D. 1994. Deconstructing the cell wall. Plant physiology, 104(4), 1113.

42. Wang, X., Rinaldi, R. 2012. Solvent Effects on the Hydrogenolysis of Diphenyl Ether with Raney Nickel and their Implications for the Conversion of Lignin. ChemSusChem, 5(8), 14551466.

43. Williams, D.L., Crowe, J.D., Ong, R.G., Hodge, D.B. 2017. Water sorption in pretreated grasses as a predictor of enzymatic hydrolysis yields. Biores Technol, 245, 242-249.

44. Williams, D.L., Hodge, D.B. 2014. Impacts of delignification and hot water pretreatment on the water induced cell wall swelling behavior of grasses and its relation to cellulolytic enzyme hydrolysis and binding. Cellulose, 21(1), 221-235.

45. Yang, B., Wyman, C.E. 2004. Effect of xylan and lignin removal by batch and flowthrough pretreatment on the enzymatic digestibility of corn stover cellulose. Biotechnol Bioengg, 86(1), 88-98.

46. Ye, Y., Zhang, Y., Fan, J., Chang, J. 2012. Selective production of 4-ethylphenolics from lignin via mild hydrogenolysis. Biores Technol, 118, 648-651. 
47. Zakzeski, J., Bruijnincx, P.C.A., Jongerius, A.L., Weckhuysen, B.M. 2010. The Catalytic Valorization of Lignin for the Production of Renewable Chemicals. Chem Rev, 110(6), 35523599.

48. Zanchet, D., Santos, J.B.O., Damyanova, S., Gallo, J.M.R., C. Bueno, J.M. 2015. Toward Understanding Metal-Catalyzed Ethanol Reforming. ACS Catal, 5(6), 3841-3863.

49. Zhang, J., Asakura, H., Rijn, J.v., Yang, J., Duchesne, P., Zhang, B., Chen, X., Zhang, P., Saeys, M., Yan, N. 2014. Highly efficient, NiAu-catalyzed hydrogenolysis of lignin into phenolic chemicals. Green Chem, 16(5), 2432-2437. 


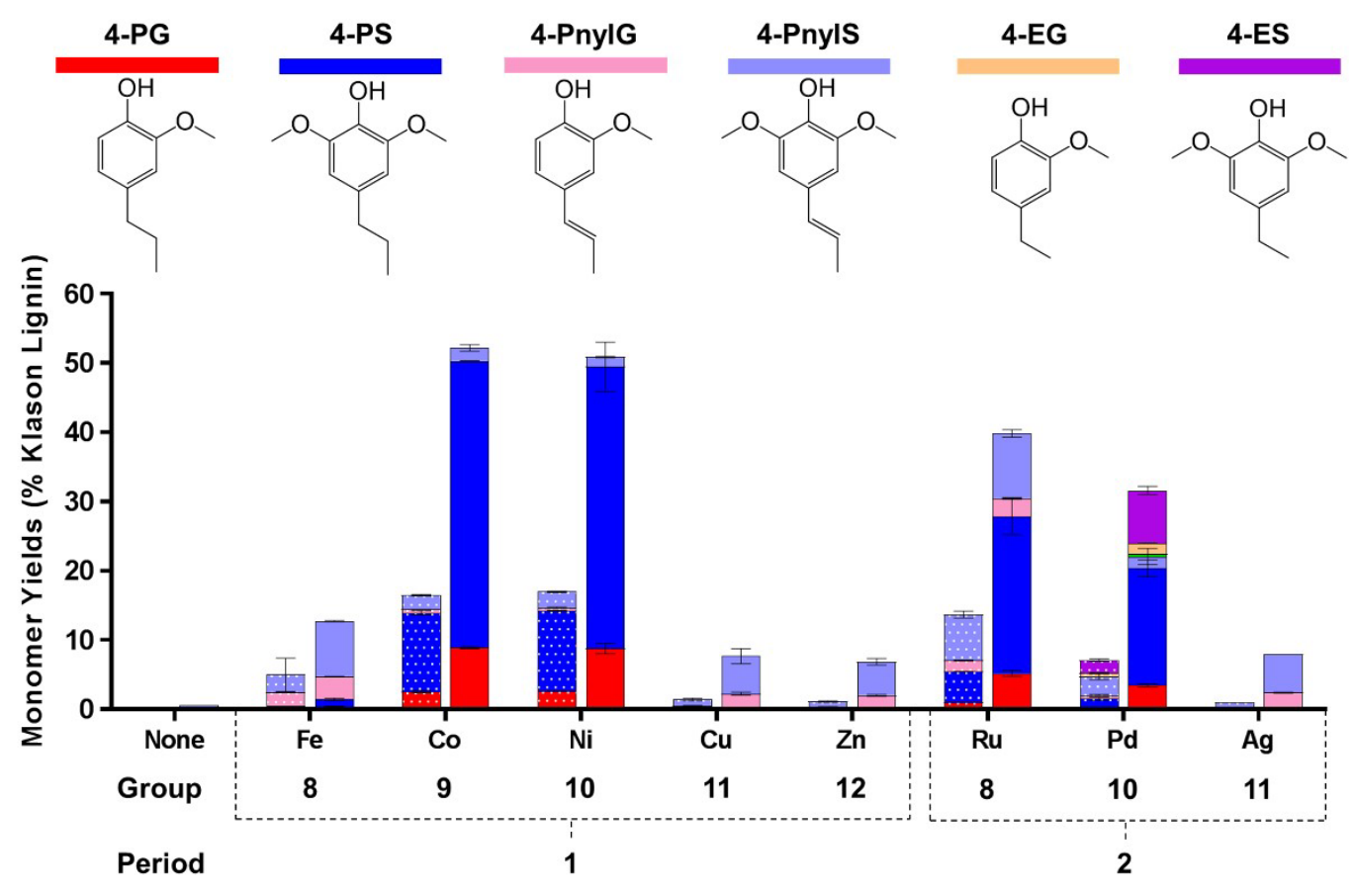




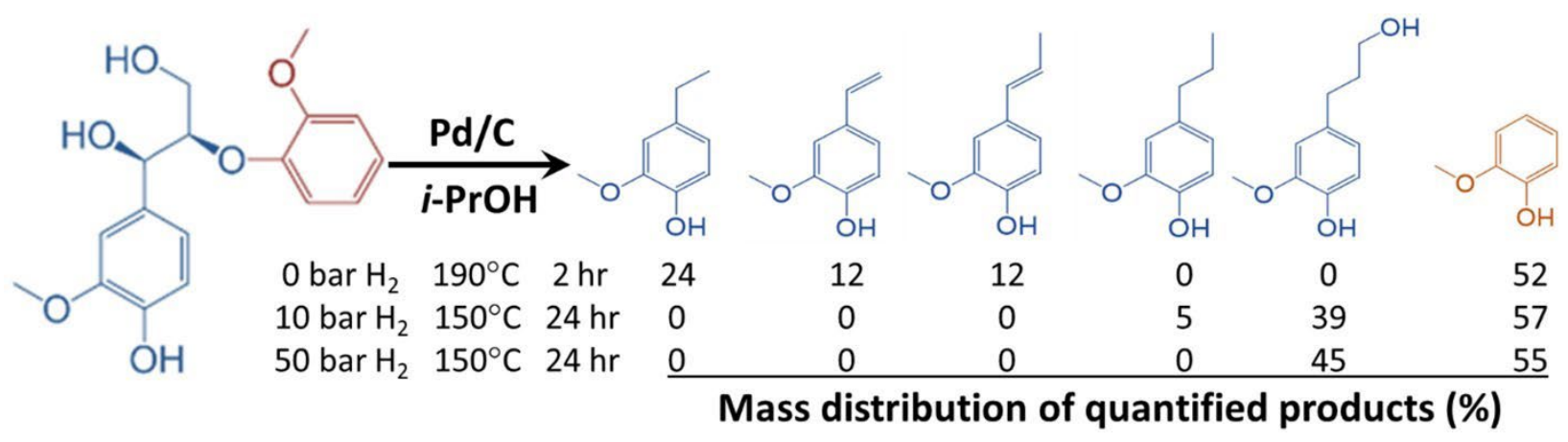



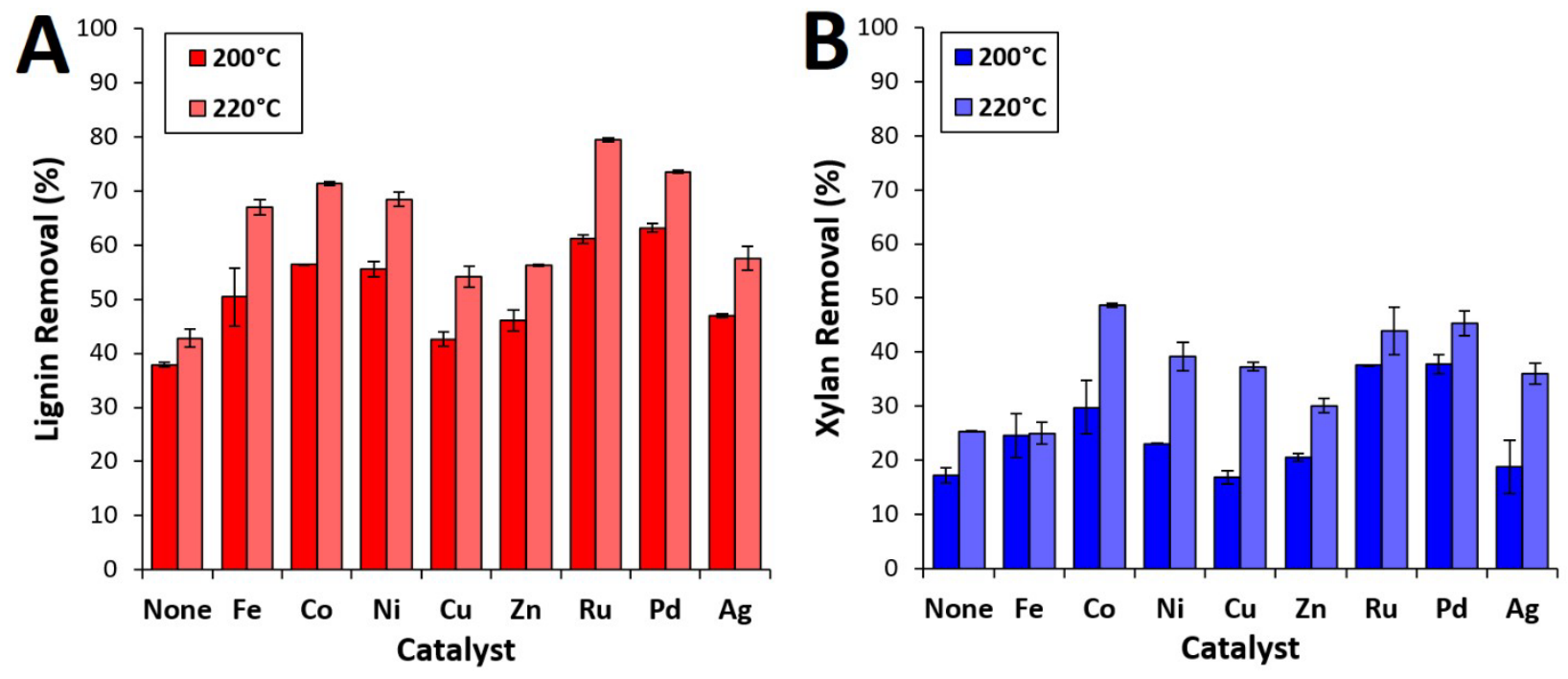

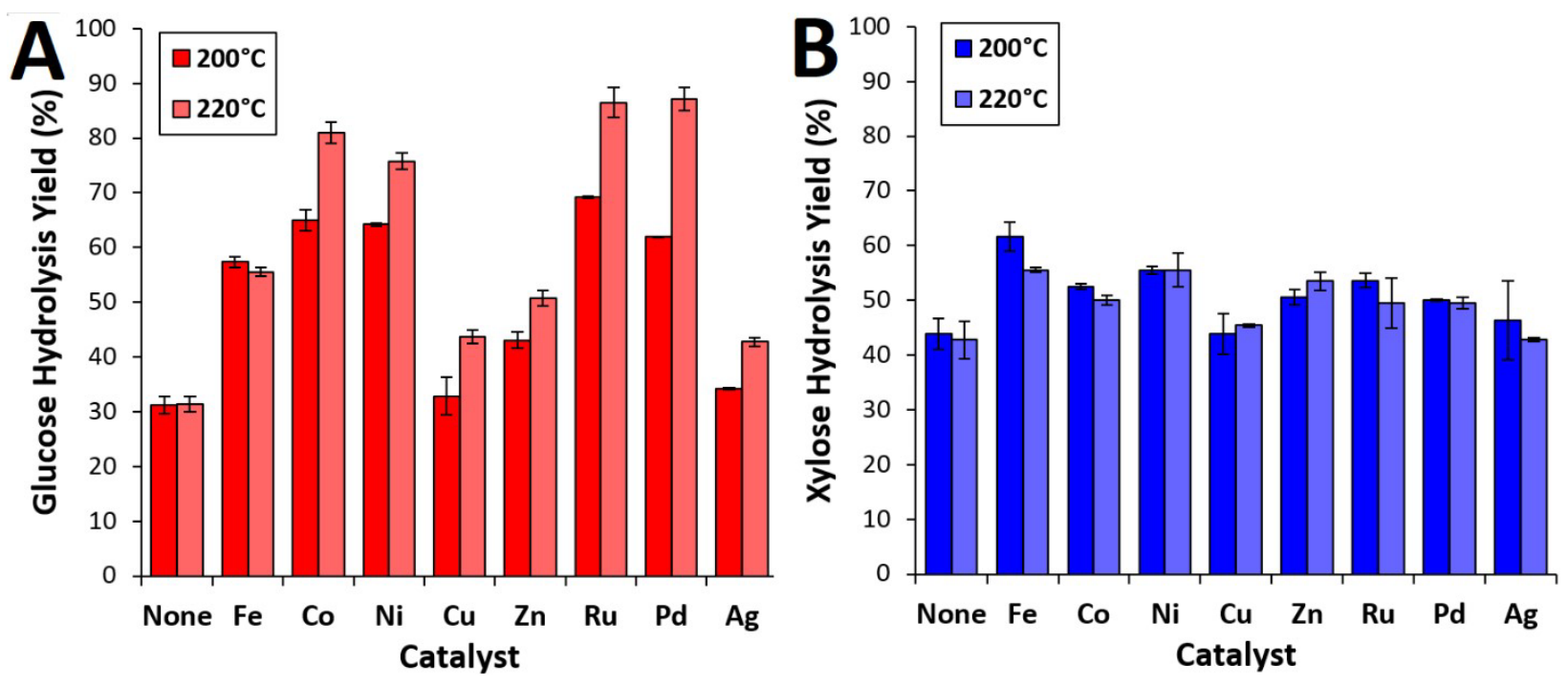

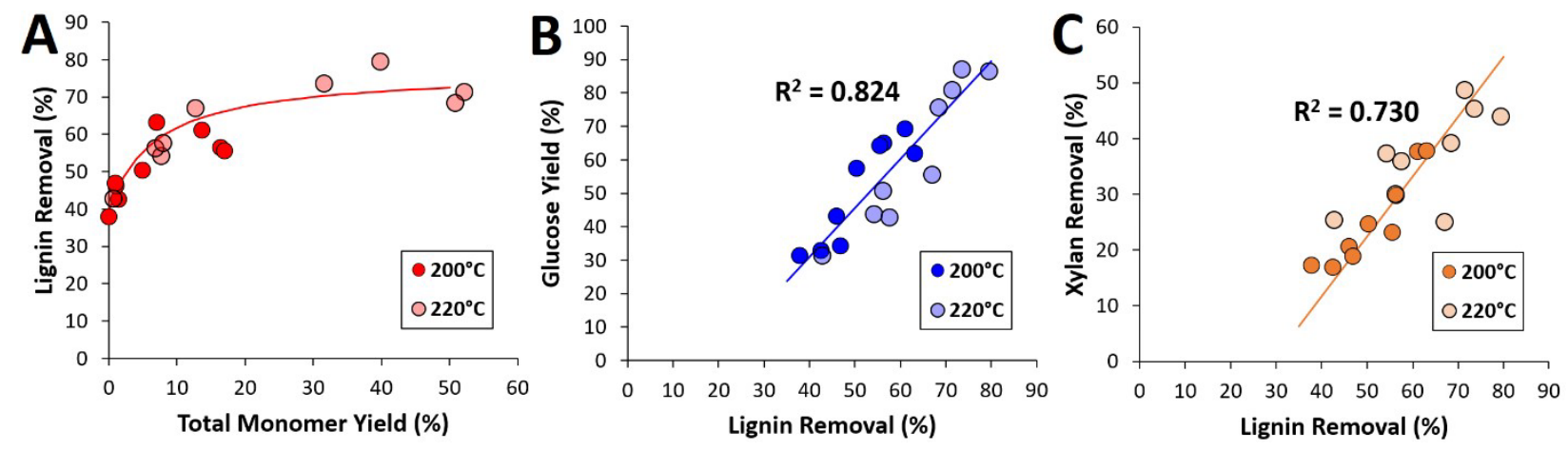


\begin{tabular}{lcc}
\hline Treatment Conditions & C/O & $\begin{array}{c}\text { Bulk Lignin-to-Polysaccharide Ratio } \\
\text { (mass/mass) }\end{array}$ \\
\hline Untreated & 3.02 & 0.43 \\
Ethanol organosolv only at $220^{\circ} \mathrm{C}$ & 2.31 & 0.27 \\
Ni/C hydrogenolysis at $220^{\circ} \mathrm{C}$ & 2.11 & 0.06 \\
\hline
\end{tabular}

Table 1: Relative surface elemental abundance and bulk lignin-to-polysaccharide ratio in untreated and pretreated birch. 